\title{
UMA ANÁLISE HISTÓRICA DO CONCEITO DE FAMÍLIA: UM ESTUDO DA GENESIS DA FAMÍLIA ATÉ A MULTIPARENTALIDADE E A FAMÍLIA CONSTITUCIONALIZADA EM SEU CONCEITO AMPLO
}

\author{
A HISTORIC ANALYSIS OF THE FAMILY CONCEPT: A STUDY OF FAMILY \\ GENESIS TO A MULTI-PARENTALITY AND A CONSTITUTIONALIZED \\ FAMILY IN ITS WIDE CONCEPT
}

\author{
Sandro Marcos Godoy'(1) \\ Murilo Aparecido Lorençoni Lima ${ }^{\mathrm{II}}$ (1) \\ Graziela Morais Cardoso ${ }^{\mathrm{III}}$ (1)
}

\begin{abstract}
${ }^{\mathrm{I}}$ Universidade de Marília (UNIMAR), Programa de Pós-Graduação Mestrado e Doutorado, Marília, São Paulo, SP, Brasil. E-mail: sandromgodoy@uol.com.br
\end{abstract}

${ }^{\text {II }}$ Universidade de Marília (UNIMAR), Marília, São Paulo, SP, Brasil. E-mail: murilolorenconi@gmail.com

III Universidade de Marília (UNIMAR), Marília, São Paulo, SP, Brasil. E-mail: grazielacardoso94@gmail.com

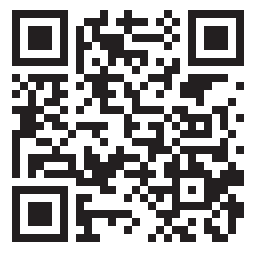

DOI: http://dx.doi. org/10.31512/rdj.v20i37.45

Recebido em: 01.08.2019

Aceito em: 20.02.2020

\begin{abstract}
Resumo: Este trabalho objetiva analisar a família desde sua gênese, advinda da associação do homem enquanto ser gregário, até a atualidade sobretudo com seus novos contornos através do reconhecimento da multiparentalidade. Ponderou-se que a família possui relevante papel na estrutura estatal, sendo um reflexo da sociedade na qual se encontra inserida. Para oportunizar o objetivo desta pesquisa fora analisado a origem histórica do conceito de família para entender como esta se apresentou durante o passar dos anos e, também, como vem se apresentado hodiernamente. O resultado desta abordagem é apresentado na pontuação de que a família é um fenômeno social e, justamente por ser um fenômeno social, irá mudar no mesmo compasso em que a sociedade mudar, sendo impossível atribuir-lhe um conceito fechado. Posteriormente, o trabalho apresentou suas consideraçóes finais as quais ponderaram que á família deve ser dado um conceito aberto, indo ao encontro tanto dos princípios constitucionais relativos à família como também abraçando as diversas formas de arranjos familiares. A pesquisa que empregou respectivamente os métodos: dedutivo, dialético, histórico e as pesquisas bibliográficas, socorreu-se das ideias de renomados pensadores do Direito como: Fredrich Engels, Lewis Henry Morgan, Antunes Varela, Rodrigo da Cunha Pereira e Paulo Lôbo dentre outros.
\end{abstract}

Palavras-chave: Família. Princípios. Multiparentalidade. Constitucional. História.

Abstract: This paper aims to analyze the family from its genesis, borning with the association of man while social animal, to the present especially with its new contours through the recognition 
of multiparenting. It was considered that the family has a relevant role in the state structure, being a reflection of the society in which it is inserted. In order to improve the objective of this research, the historical origin of the family concept was analyzed to understand how it presented itself over the years and also how it has been presented today. The result of this approach is presented with the conclusion that the family is a social phenomenon and, precisely because it is a social phenomenon, will change at the same time as society changes, being impossible to attribute a closed concept to it. Subsequently, the paper presented its final considerations which contemplate that the family should be given an open concept, meeting both the constitutional principles concerning the family and also embracing the various forms of family arrangements. The research that employed respectively the methods: deductive, dialectical, historical and the bibliographical researches, used the ideas of renowned thinkers of the Law as: Fredrich Engels, Lewis Henry Morgan, Antunes Varela, Rodrigo da Cunha Pereira and Paulo Lôbo among others.

Keywords: Family. Principles. Multiparenting. Constitutional. History.

\section{Consideraçóes iniciais}

A família possui intrínseca relação com o desenvolvimento histórico da humanidade. Tendo em vista que entidade familiar guarda relação com as fundações da sociedade e esta, por sua vez, do Direito delimitar o conceito desse instituto é, no mínimo relevante, em um estado democrático de direito.

Com efeito, relevante se mostrou uma análise detalhada da gênese da família, de modo que o trabalho percorreu tanto os aspectos históricos desta quanto os contornos que essa instituição recebeu nos tempos atuais, culminado na família constitucionalizada e no reconhecimento da multiparentalidade.

Destarte, oportuno se fez analisar diferentes momentos da humanidade, tendo como parâmetro os arranjos familiares e como que a sociedade da época repercutia em sua constituição e na dinâmica de suas relaçóes.

Em um primeiro momento, o trabalho concentrou sua atenção para analisar períodos antropológicos como selvageria, barbárie e civilização, sempre relacionados ao papel que a família ocupou neles.

Nesse sentido, oportuno foram as ponderaçóes acerca de como as mutaçóes sociais tendem a interferir na maneira como os arranjos familiares se apresentam na sociedade hodierna, sobretudo em como esta fora constitucionalizada e protegida pelo Estado. 
Com o intuito de viabilizar esta reflexão, ponderou-se que a Constituição Federal traz um conceito amplo de família, justamente por reconhecer que a família, enquanto fenômeno social, está em constante mutação e conceituá-la de maneira fechada seria limita-la.

Para oportunizar a análise proposta por este trabalho, o estudo em tela utilizou informações literárias, comparação de dados e análise de pesquisas já feitas por outros pesquisadores tais como: Engels, Lewis Henry Morgan, Antunes Varela, Rodrigo da Cunha Pereira e Paulo Lôbo.

O escopo deste trabalhou girou em torno de analisar como os arranjos familiares se apresentaram no decorrer dos tempos, outrossim, foi de preocupação deste trabalho analisar como a mudança da sociedade repercute na composição da família, motivo pelo qual a proteção Estatal deve ser dada de maneira ampla. No mais, foram objetos desta pesquisa o surgimento da multiparentalidade como entidade familiar e a família constitucional, uma vez que aquela representa um exemplo de como a evolução da sociedade pode repercutir no modo como a família se apresenta.

A justificativa para a escolha do tema repousa na maneira como ele se apresenta enraizado nas estruturas estatais, sendo a família o berço da sociedade e a garantidora de propagá-la de forma ordenada. Nesse sentido, o estudo da multiparentalidade sob o manto da família constitucional iluminou o debate acerca de um conceito de família amplo, o qual abrange a multiparentalidade, uma vez que referida conclusão repousa em uma análise critica da própria origem e essência da família, qual seja: a mutação de acordo com a mudança dos tempos.

No mais, a explicação para analisar o conceito de família desde sua gêneses até os dias atuais e com especial enfoque na a ideia de multiparentalidade e da família constitucionalidade justificou-se na percepção de que os arranjos familiares se mostram tão caros ao Estado Democrático de Direito a ponto de receberem proteçáo Constitucional. Deste modo, restou justificado o fato do trabalho correlacionar as noçóes históricas do surgimento familiar com a análise hodierna da multiparentalidade como sendo um novo modelo de família reflexo da mudança dos tempos.

A análise em tela preocupou-se em tratar do objeto de estudo de uma forma sequencial e motivada. Para que seja viabilizada esta preocupação, a pesquisa lançou mão de alguns métodos científicos, sendo eles: indutivo, dialético, histórico, descritivo, jurisprudencial e bibliográfico.

O presente estudo sistematizou-se em 4 partes. A primeira parte do estudo cuidou da introdução do tema. A segunda parte intitulada de "uma análise histórica: a origem da família” trouxe uma perspectiva da família através dos tempos. A terceira parte preocupouse com em pontuar como a família mudou através dos tempos e quais as consequências vieram desta mudança, sendo intitulada de: “A Família Através dos Tempos: O Conceito 
Amplo de Família, a Família Constitucionalizada e a Multiparentalidade”. Por fim, a quarta parte versou sobre as conclusóes da pesquisa.

\section{Uma análise histórica: a origem da família}

A gênese familiar guarda historicidade tão extensa quanto a própria humanidade. Isto porque a entidade familiar foi o berço estrutural da sociedade e esta, por sua vez, do Direito.

Aristóteles (2008, p. 56) no correr de seus estudos concluiu que o homem é um animal político, haja vista que possui uma inclinação intrínseca de conviver com seus semelhantes. Para ele a raiz desta característica está na fala, onde a comunicabilidade humana não se restringe a mera emissão de sons, mas a radiação de uma mensagem, fator responsável pela agregação dos indivíduos.

Da uniáo de indivíduos emergiu a família, sendo esta a responsável pela gênese e desenvolvimento da sociedade e, consequentemente, do Direito (vide o brocardo romano "ubi jus, ibi societas, ubi societas, ibi jus", isto é, onde há direito há sociedade, onde há sociedade há direito) (CARDOSO, 2016, p.10).

Nesse sentido, John Rawls (1999, p. 157) aponta que "a família é parte da estrutura básica, uma vez que um de seus principais papéis é ser a base de produção e reprodução ordenada da sociedade e sua cultura de uma geração para a seguinte" ${ }^{1}$.

Sobre o tema, preleciona, outrossim, Francesco Carnelutti (2006, p. 53):

A pretensão, dentre outras coisas, de negar a família para afirmar o Estado é uma das mais insanas aberraçôes que podem ser adotadas na história do pensamento humano. Sem a família, o Estado não pode viver, como não se poderia construir um edifício se se desagregassem os tijolos com que ele é construído. Um Estado sem família é tão absurdo quanto um corpo humano sem células. Assim como a saúde do corpo humano depende da permeabilidade da célula do misterioso fluxo vital, também a saúde do Estado depende da coesão da família, ou seja, da circulação do amor entre seus membros.

Ademais, Roberto Lyra Filho (2006, p. 12) assevera que os fenômenos sociais não seguem um modelo fixo. Ao revés, mantêm-se em constante movimento e contínua transformação. Nessa toada, segue o Direito o mesmo corolário lógico explicitado, onde inexiste "ser", apenas "sendo".

Tendo em vista que a família é um fenômeno social, chega-se a mesma conclusão filosófica dada ao Direito: houve, há e haverá frequentes e ininterruptas transformações.

Sob a perspectiva histórica, por sua vez, ao menos quanto ao passado podemos afirmar: desde a origem até os dias atuais, a família passou por diversas mutaçóes.

1 "The family is part of the basic structure, since one of its main roles is to be the basis of the orderly production and reproduction of society and its culture from one generation to the next". 
Lewis Henry Morgan (1877, p. 519), considerado um dos fundadores da antropologia moderna, dividiu a humanidade em três períodos: selvageria, barbárie e civilização. Salientou que estes períodos aconteceram de formas sucessivas com vagarosas somatizaçóes do conhecimento experimental. Em seu estudo, concluiu que na préhistória vigorava a liberdade sexual entre os membros da tribo.

Ainda nessa senda, referido pensador enunciou que a família monogâmica só foi fazer sua primeira aparição no estado superior da barbárie e se deu em razão do crescimento da propriedade e por questóes relativas à herança (MORGAN, 1877, p. 563). Neste viés, assevera igualmente Engels (1986, p. 66):

A concepção tradicional conhece apenas a monogamia, ao lado da poligamia do homem e talvez da poliandria de uma mulher, silenciando - como convém ao filisteu moralizante - sobre o fato de que na prática aquelas barreiras impostas pela sociedade oficial sáo tácita e inescrupulosamente transgredidas. $\mathrm{O}$ estudo da história primitiva revela-nos, ao invés disto, um estado de coisas em que os homens praticam a poligamia e as suas mulheres a poliandria, e em que, por consequência, os filhos de uns e outros tinham que ser considerados comuns. É este estado de coisas, por seu lado, que, passando por uma série de transformaçôes, resulta na monogamia. Essas modificações são de tal ordem que o círculo compreendido na união conjugal comum, e que era muito amplo na sua origem, se estreita pouco a pouco até que, por fim, abrange exclusivamente o casal isolado, que predomina hoje.

Com o estudo desses autores, conclui-se que a monogamia foi uma construção humana que se deu de forma bastante lenta e surgiu para possibilitar a transmissão de herança.

Após a pré-história, iniciou-se a Antiguidade com a invenção da escrita. Neste período histórico duas civilizações ganharam destaque: a grega e a romana.

Os clãs, formados pela união de indivíduos com relação de parentesco, foram a primeira etapa da estruturação social na Grécia antiga. Eles possibilitaram a formação das polis, também conhecidas como cidades-estados, as quais apresentavam mecanismos de organização política diversos, ou seja, eram independentes politicamente umas das outras. Todavia, uniam-se no aspecto cultural, especialmente quanto à língua, costumes e valores comuns (ACKER, 1994, p. 08).

Os helenos viviam sob o manto de uma sociedade patriarcal, onde as mulheres possuíam uma vida reclusa, ligada, no mais das vezes, aos afazeres domésticos. Nessa linha, Maria Teresa Vianna Van Acker (1994, p. 21) enuncia que homens e mulheres ocupavam espaços diferentes, tais quais os deuses Héstia e Hermes. Héstia era relacionada a lareira central da casa, enquanto Hermes, por sua vez, era posto na soleira das portas, vinculado ao lado exterior.

Além de exteriorizar a cultura patriarcal, nota-se que a religiosidade estava diretamente relacionada a todas as instituiçóes existentes na sociedade helênica, inclusive a família. 
Em Roma, por sua vez, a família era constituída por todos os indivíduos que estavam sob a autoridade do mesmo chefe: o paterfamilias. Ele ostentava uma imensidão de poderes, o que aproximava a estrutura familiar romana a que conhecemos do Estado soberano (VARELA, 1999, p. 44).

Séculos mais tarde, na idade média, conforme leciona Antunes Varela (1999, p. 47) a emersão do sistema feudal associada à modificaçáo da doutrina religiosa implicou numa série de mudanças comportamentais. Num viés diametralmente oposto ao individualismo que se perfazia na idade antiga, a sociedade medieval regia-se por um espírito comunitário, onde a família possuía função produtiva. A instituição familiar abandonou sua constituição como organismo político e transformou-se em uma comunidade natural vinculada pelo matrimônio religioso (de natureza perpétua) e pelos laços biológicos oriundos da procriação. $\mathrm{O}$ poder estava nas mãos da igreja, de modo que ela estabelecia todo o regramento moral e jurídico a ser seguido pelo povo. Neste modelo, também competia a mulher a educação dos filhos e os trabalhos domésticos.

Com a tomada de Constantinopla pelos turcos otomanos, iniciou-se a idade moderna e esta representou um período de transição do sistema feudal para o sistema capitalista. Nessa época, a monarquia prevaleceu enquanto regime político e a Igreja Católica perdeu significativamente seu poder. Em que pese todas as alteraçóes existentes na esfera cultural, as mulheres foram mantidas no trabalho doméstico e a família alterouse pouco (PINTO, 2015 s.p).

Hodiernamente, novas mudanças foram impetradas na instituição familiar. Desta vez, contudo, as mudanças são tão vastas e significativas que implicaram na emersão das mais diversas modalidades de família. Todas essas alterações estão diretamente relacionadas à aquisição dos direitos femininos. Tal fato só foi possível com a revolução industrial, já na idade contemporânea, quando as mulheres saíram da dedicação exclusiva ao trabalho doméstico e criação de filhos, e passaram a exercer, ainda que timidamente, atividades laborativas fora de seus respectivos lares.

Antes da promulgação da atual Constituição, houve algumas poucas conquistas na seara jurídica do Brasil, tal como a possibilidade das mulheres votarem em 1932 com a previsáo no Código Eleitoral e, pouco depois, em 1934 com a constitucionalizaçáo deste direito. No entanto, o ápice foi atingido recentemente com a efetiva equiparaçáo dos direitos femininos aos masculinos por meio da Constituição de 1988 e o Código Civil de 2002.

A igualdade feminina, somada à gênese da lei do divórcio em 1977, culminou numa realidade plural, onde a diversidade de arranjos familiares ruiu com o modelo único e engessado vigente nos tempos pretéritos.

É importante destacar em relação à desigualdade feminina que o discrímen não decorre como se pensava, de uma parcela de homens rudes e inóspitos culturalmente: 
Assim, tinha-se que a desigualdade de tratamento da mulher, inclusive no mercado de trabalho, não passava de uma questão cultural e restrita a uma camada de homens inóspitos à isonomia feminina, de cultura rude e insensíveis.

No entanto, o discrimen contra a mulher tem-se mostrado presente também entre os intelectuais do nosso tempo, homens de cultura elevada e prósperos intelectuais modernos. (GODOY, 2015, p. 32)

Sobre o tema, arrazoam Novelino e Cunha Júnior (2017, p. 226):

A dissolução do casamento tem por objetivo permitir que seja contraído um novo vínculo. Conforme a precisa reflexão feita por Antônio Pereira Jr. (2009), a independência econômica resultante da expansão da atuaçáo feminina no mercado de trabalho e a autonomia reprodutiva ampliada pelos métodos contraceptivos fizeram com que a dimensão afetivo-sentimental do casamento ganhasse uma maior relevância, tornando o divórcio um procedimento acessível para os casos de diminuição ou ausência de afetividade.

Algo antes não retratado pelo nosso antigo código e fortemente repreendido pelas demais instituiçóes, atualmente é agasalhado pela nossa Constituição e, aos poucos, vem ultrapassando as barreiras do preconceito (CARDOSO, 2016, p. 16).

Todavia, não se pode ignorar a lentidão legislativa que, junto às rápidas mudanças, máxime no Direito de Família, culminou em deixar inúmeras lacunas. Nesse sentido, assevera Dias (2011, p. 27):

Mesmo sendo a vida aos pares um fato natural, em que os indivíduos se unem por uma química biológica, a família é um agrupamento informal, de formação espontânea no meio social, cuja estruturação se dá através do direito. Como a lei vem sempre depois do fato, congela uma realidade dada. As modificações da realidade acabam se refletindo na lei, que cumprem sua vocação conservadora. A família juridicamente regulada nunca é multifacetada como a família natural. Essa preexiste ao Estado e está acima do direito. A família é uma construção cultural. Dispóe de estruturação psíquica na qual todos ocupam um lugar, possuem uma função - lugar do pai, lugar da mãe, lugar dos filhos -, sem, entretanto, estarem necessariamente ligados biologicamente. É essa estrutura familiar que interessa investigar e trazer para o direito. É a preservação do $L A R$ no seu aspecto mais significativo: Lugar de Afeto e Respeito.

A vida é mais criativa que o Direito, ainda mais na modernidade em que o afeto é um dos pilares da família. Ora, se a função política e produtiva se perdeu, restou o afeto às famílias atuais como liame entre seus membros (CARDOSO, 2016, p. 16).

No mais, todo o esposado alhures pode ser bem resumido nos dizeres da magistrada Andréa Pachá (2016, p.74) que ilumina a temática desta pesquisa afirmando que: "as múltiplas formas de paternidade e as mais diversas manifestaçóes de amor, se conjugadas, fortalecem uma sociedade democrática. É, no fim, uma equação simples. Quanto mais afeto, maior a possibilidade de justiça” 
Isto posto, observa-se que as inovações se acentuaram, de modo a formar esta sociedade pluralista, com diversas incógnitas quanto à tutela jurídica a cada novo arranjo familiar que emergir e bater na porta do judiciário.

\section{A família através dos tempos: o conceito amplo de família, a família constitucionalizada e a multiparentalidade}

Sociologicamente, é impossível definir um conceito absoluto de família, isto é, atribuir-lhe um conceito certo, determinado e perene. Conforme mostrado anteriormente, a maneira de se conceber a família muda de acordo com a mudança dos tempos.

Isto porque o mesmo não é uma ideia congelada, atemporal. Pelo contrário: ele muda conforme a era, local e cultura vivenciada. Nesse viés, Marco Túlio de Carvalho Rocha (2009, p. 55) aponta que o conceito de família é "fundamentalmente sociológico e variável”.

Juridicamente, no entanto, é sempre possível conceituar. Se assim quiser o legislador ou o constituinte, pode-se conceber expressamente uma ideia geral e abstrata de família. Consequentemente, todos os grupos que não se encaixarem no conceito prémoldado, não serão família para os fins legais.

A família pré-constituição de 1988 caracterizava-se por ser matrimonializada, patriarcal, hierarquizada, heteroparental e biológica, consistente numa unidade de produção e reprodução de caráter institucional (FARIAS; NETTO; ROSENVALD, 2019, p. 1693).

A Constituição Federal vigente, por sua vez, trouxe em seu art. 226 a qualificação da família como base da sociedade. Além disso, enfatizou que a mesma tem especial proteção do Estado, o que, per si, já veda a exclusão de uma espécie familiar pelo judiciário.

No entanto, observa-se que a mesma Constituição Federal optou por não conceituar expressamente família. Ao revés, trouxe um conceito implícito, oriundo de uma interpretação sistemática de todo seu teor, na qual se extrai os valores normativos constitucionais, de alguns princípios constitucionais, especialmente: dignidade da pessoa humana, solidariedade, igualdade, afetividade e pluralidade das formas de família.

Desse modo, extrai-se de todo conteúdo normativo desses princípios que: 1) a Constituição é centrada no homem e o prioriza enquanto ser dotado de dignidade; 2) a consagração dos direitos de terceira dimensão repercute na família com a responsabilidade social entre seus membros; 3) a discriminação negativa é vedada, pois ela intensifica a desigualdade e marginaliza grupos e pessoas. Permite-se apenas a discriminação positiva, materializada em açóes afirmativas, haja vista que esta consubstancia a igualdade material; 4) o afeto ecoa como base fundante da família moderna. Sobreleva, assim, a função existencial da família; 5) não há limitação da composição familiar. Todas as formas de 
famílias estão constitucionalmente tuteladas, pois a Constituição trouxe um conceito aberto.

Logo, denota-se que a existência humana digna com responsabilidade social e tratamento igualitário acrescidos da afetividade e da busca pelo desenvolvimento da personalidade dos integrantes da família são as balizas circundantes da família constitucionalizada.

Quanto ao tema, Cristiano Chaves de Farias, Felipe Braga Netto e Nelson Rosenvald (2019, p. 1692) sustentam que:

A arquitetura da sociedade moderna impóe um modelo familiar descentralizado, democrático, igualitário e desmatrimonializado. Funda-se a família pós-moderna em sua feição jurídica e sociológica, no afeto, na ética, na solidariedade reciproca entre os seus membros e na preservação da dignidade deles. Esses são os referenciais da família contemporânea.

A leitura da nossa sociedade importa muito na estrutura da família. A família esta inserida na sociedade de modo que todo o designe daquela é influenciado por esta e vice-versa.

Uma conjuntura familiar autoritária é dotada de um sistema falido incompatível com a modernidade. Com a família dotada de função social, todos os referenciais mudam. Os sentimentos e a voz de cada integrante ganham relevância. Desse modo, os integrantes da família moderna perquirem a felicidade pessoal e social, o que reforça a sua função existencial. Tal particularidade fez emergir a família eudemonista como novo modelo familiar e aproximou o conceito jurídico de família com o seu conceito sociológico.

Como a priori dito, é impossível atribuir um conceito sociológico certo, determinado e perene de família. Por isso andou bem a Constituição em não engessar a família num conceito expresso.

Ora, não há um único matiz no conceito de família. Assim, a estrutura paradigmática aberta permite que outros ninhos ou arranjos familiares socialmente construídos sejam reconhecidos (GAGLIANO; PAMPLONA FILHO, 2017, p. 1122).

Trata-se de uma família pluralizada, democrática, igualitária substancialmente, hetero ou homoparental, biológica ou socioafetiva, consistente numa unidade socioafetiva de caráter instrumental (FARIAS; NETTO; ROSENVALD, 2019, p. 1693).

Dentro dessa temática, Pablo Stolze Gagliano e Rodolfo Pamplona (2017, p. 1123-1124) elucidam:

É preciso compreender que família, hoje, não é um fim em si mesmo, mas o meio para a busca da felicidade, ou seja, da realização pessoal de cada indivíduo, ainda que existam - e infelizmente existem - arranjos familiares constituídos sem amor.

$\mathrm{O}$ que não se pode prescindir, nesse contexto, é o seu intrínseco elemento teleológico consistente na formação de um núcleo existencial que tenha por finalidade 
proporcionar uma tessitura emocional (e afetiva) que permita a realização da família como comunidade e dos seus membros como indivíduos.

Explicam, outrossim, Cristiano Chaves de Farias, Felipe Braga Netto e Nelson Rosenvald (2019, p. 1693):

A família existe em razão de seus componentes, e não estes em função daquela, valorizando de forma definitiva e inescondível a pessoa humana. É o que se convencionou chamar de família eudemonista, caracterizada pela busca da felicidade pessoal e solidária de cada um de seus membros. Trata-se de um novo modelo familiar, enfatizando a absorçấo do deslocamento do eixo fundamental do Direito das Famílias da instituição para a proteção especial da pessoa humana e de sua realização existencial dentro da sociedade.

Desse modo, conclui-se que a família é o local onde cada pessoa surge e se desenvolve física, psíquica e afetivamente.

Sobre o afeto, João Baptista Villela (1979, p. 16), precursor na defesa da paternidade socioafetiva, assevera que "há um nascimento fisiológico e, por assim dizer, um nascimento emocional. É neste, sobretudo, que a paternidade se define e se revela”.

Desta feita, o efetivo desempenho parental está na socioafetividade. Esta é a prática responsável por desencadear o vínculo jurídico da maternidade ou paternidade. Desse modo, João Baptista Villela (1979, p. 413) afirma ainda que:

Chegados à plenitude desse novo estágio, os filhos, mais do que nunca, serão experimentados náo como o salário do sexo, mas como o complemento livremente buscado e assumido de um empenho de personalização, que lança suas raízes no mais poderoso dinamismo transformacional do homem, que é o dom de si mesmo.

Dentre as inúmeras consequências proporcionadas pela parentalidade socioafetiva, está a multiparentalidade, uma vez que a parentalidade socioafetiva pode ser exercida em conjunto com a biológica, ou seja, dois indivíduos podem ocupar idêntica função parterno-filial ou materna-filial.

Majoritariamente esta possibilidade recai em famílias reconstituídas, as quais nascem necessariamente após a decomposição de um arranjo familiar prévio.

Nesse viés, Cristiano Chaves de Farias, Felipe Braga Netto e Nelson Rosenvald afirmam (2019, p. 1704):

As famílias reconstituídas (ou, como preferem os argentinos, familias ensabladas, stepfamily, em vernáculo inglês ou, ainda, na linguagem francesa, famille recomposée) são entidades familiares decorrentes de uma recomposição afetiva, nas quais, pelo menos, um dos interessados traz filhos ou mesmo situações jurídicas decorrentes de um relacionamento familiar anterior. É o clássico exemplo das famílias nas quais um dos participantes é padrasto ou madrasta de filho anteriormente nascido. É também o exemplo da entidade familiar em que um dos participantes presta alimentos ao excônjuge ou ao ex-companheiro.

Dentro das famílias reconstituídas, emerge a pluriparentalidade como uma de suas espécies, impulsionada pelo reconhecimento da igualdade de gêneros em direitos 
e obrigações, bem como pela lei do divórcio. Acerca disso, elucidam Jussara Suzi Assis Borges Nasser Ferreira e Konstanze Rörhmann (2008, p. 02):

As famílias pluriparentais, também conhecidas como famílias mosaicos, famílias patchwork (Alemanha), famílias ensambladas (Argentina), step-families (Estados Unidos), familles recomposées (França), representam o mais novo e desafiante modelo familiar já conhecido pelo Direito de Família. As famílias pluriparentais resultam da pluralidade das relaçóes parentais, especialmente fomentadas pelo divórcio, pela separação, pelo recasamento, seguidos das famílias não-matrimoniais e pelas desuniões. A estrutura das recomposiçōes familiares vem caracterizada por matrimônios ou uniōes sucessivas e a presença de filhos de outras relaçóes.

A pluriparentalidade consiste na existência de mais de um pai e/ou mais de uma mãe com todos os efeitos decorrentes desta condição.

Não se confunde com a bimaternidade ou bipaternidade, situação em que casais homossexuais adotam uma criança. O enquadramento na definição de multiparentalidade demanda, pelo menos, três pessoas.

Nessa esteira, não há como estabelecer uma base rígida de modo que a multiparentalidade seja resultado de uma equação matemática. Contudo, alguns critérios podem ser apontados para tanto, sem o escopo de esgota-los, é de interesse desta pesquisa discorrer sobre alguns deles, tais como: legitimidade para requerimento, filiação biológica e/ou afetiva e fundamento constitucional.

No tocante ao primeiro critério, o art. 27 do Estatuto da criança e do adolescente prevê que "o reconhecimento do estado de filiação é direito personalíssimo, indisponível e imprescritível, podendo ser exercitado contra os pais ou seus herdeiros, sem qualquer restrição, observado o segredo de Justiça”. Ainda, o 1.606 do Código Civil preceitua que "a ação de prova de filiação compete ao filho, enquanto viver, passando aos herdeiros, se ele morrer menor ou incapaz".

Nesse interim, por meio de uma interpretação literal dos artigos, conclui-se que a legitimidade ativa é exclusiva do filho. Todavia, a interpretação adequada é a conforme a Constituição, tendo por base princípios como o da dignidade da pessoa humana, da proteção integral, da paternidade responsável e da equidade (haja vista que uma relação é necessariamente bilateral), de modo que a legitimidade ativa pertence aos pais e aos filhos

Por seu turno, a presença do critério biológico e/ou afetivo no vínculo materno ou paterno-filial decorre do corolário lógico de que é necessário um elo entre as partes envolvidas (SCHWERZ, 2015).

Acerca do tema, Paulo Lôbo (2004) entende que a única paternidade existente é a afetiva, e esta pode ser biológica ou não. Contudo, o STF não acampou este entendimento. Para o pretório excelso, a paternidade pode ser tanto afetiva quanto biológica.

Finalmente, o terceiro critério é o do fundamento constitucional. Ele demanda que o caso concreto seja compatível com a vontade constitucional, ou seja, verifica se 
neste a multiparentalidade é, dentre as opçóes de decisões possíveis, a que se coaduna com as normas constitucionais (SCHWERZ, 2015).

Insta salientar que a multiparentalidade diferencia-se, outrossim, da adoção, haja vista que nesta há um vínculo rompido, enquanto naquela há o um vínculo somado/ acrescido. Ademais, a adoção carrega apenas os impedimentos para o casamento, enquanto que na pluriparentalidade todos os efeitos ordinários da filiação são abrangidos, pois se trata de uma filiação como qualquer outra.

Ainda no tocante à diferenciação entre a adoção e a multiparentalidade, sobretudo no que tange ao seu fator mais marcante, qual seja, a ruptura do vínculo naquela e o acréscimo do mesmo nesta, é mister salientar que a adoção unilateral passa a configurarse como um instrumento obsoleto haja vista a possibilidade de reconhecimento da multiparentalidade, uma vez que referida modalidade de adoção iria contra o melhor interesse da criança adotada. Por seu turno, a sua substituição pela pluriparentalidade traria vantagens inegáveis ao infante (GESSE, 2019).

Por fim, vale pontuar que o parentesco, vínculo tão relevante juridicamente, não se fecunda em qualquer interação esporádica. É necessária forte relação, de modo que haja uma construçáo cultural daquele ser humano que reconhece o outro como pai ou como mãe, bem como igual reconhecimento social na comunidade em que estes indivíduos estão inseridos.

Toda alteração fática dentro de uma família invariavelmente repercute na mesma. São as partes envolvidas que protagonizam os acontecimentos e que sofrem diretamente com seus efeitos.

Desta feita, reconhece-se que esta nova modalidade familiar emergiu da sociedade. Entretanto, compete aos tribunais reconhecê-la, respeitando o conceito constitucional aberto de família, e aplicá-la, utilizando da interpretação e analogia nos princípios e regras para resolver de forma justa as consequências que surgirão desse novo modelo familiar.

A existência da multiparentalidade na esfera jurídica foi reconhecida pelo STF no RE 898.060. Nesse julgado, fixou-se a tese de que a paternidade socioafetiva,sendo esta constada ou não no registro público, não tem o condão de impedir que seja admitido o vínculo de filiação biológica.

Nessa senda, traçando uma análise do framework da decisão mencionada alhures, pontua-se que o caso enfrentado pelo STF detinha certa peculiaridade. Além dos vastos efeitos intrínsecos ao reconhecimento da multiparentalidade, chamou atenção a situação de a pluriparentalidade ser admitida "de acordo com o exclusivo interesse do filho, mesmo não havendo sido construída história de vida alguma com o pai biológico" (GAGLIANO; PAMPLONA FILHO, 2017, p. 1370). 
Como exaustivamente defendido no presente trabalho, o ministro relator Luiz Fux asseverou em seu voto que a família constitucionalizada impede que a multiparentalidade fática seja ignorada na órbita jurídica² ${ }^{2}$.

Em diversos momentos ele explicitou a impossibilidade de reduzir as realidades familiares a modelos pré-concebidos. Isto porque o direito à busca pela felicidade impede que o indivíduo seja reduzido a mero instrumento da vontade do governante. Asseverou, igualmente, que omissão legislativa não é fundamento para o não reconhecimento de uma modalidade familiar. Por conseguinte, os modelos familiares citados na Constituição não excluem outros, de modo que o rol existente é meramente exemplificativo.

Ademais, frisou que o macroprincípio da dignidade da pessoa humana incide sobre todo ordenamento jurídico, inclusive na interpretação das normas constitucionais.

Por fim, interessante também enfatizar que o ministro relator fundamentou-se também no Direito Comparado, citando o Estado norte-americano de Louisiana que foi o primeiro de seu país a permitir legalmente que um filho tenha dois pais, após revisar seu Código Civil estadual em 2005 devido à consolidação da jurisprudência nesse sentido.

Desta feita, acerca da tutela jurídica das vastas composiçôes familiares, a essência da decisão do Supremo Tribunal Federal é que a existência de um vínculo parental não automaticamente exclui outro.

Porém, ainda assim há relutância nos tribunais, motivada, mormente, pelas polêmicas consequências que a multiparentalidade pode acarretar. Isto porque não há legislação específica tratando da multiparentalidade. Este fator, no entanto, não pode inviabilizar a sua aplicação na jurisdição, conquanto isto feriria a família constitucionalizada.

Com este ideal assertivo, apregoa Mauricio Cavallazzi Póvoas (2012, p. 79):

No que tange a possibilidade da coexistência de vínculos parentais afetivos e biológicos, essa se mostra perfeitamente viável e, mais do que apenas um direito, é uma obrigação constitucional na medida em que preserva direitos fundamentais de todos os envolvidos, sobretudo, as já debatidas dignidade e afetividade da pessoa humana.

Ana Carolina Brochado Teixeira e Renata de Lima Rodrigues (2013, p. 21) também defendem essa possibilidade:

Defendemos a multiparentalidade como alternativa de tutela jurídica para um fenômeno já existente em nossa sociedade, que é fruto, precipuamente, da liberdade de (des) constituição familiar e da conseqüente formação de famílias reconstituídas. A nosso sentir, a multiparentalidade garante aos filhos menores que, na prática, convivem com múltiplas figuras parentais a tutela jurídica de todos os efeitos que emanam tanto da vinculaçáo biológica como da socioafetiva, que, como demonstrado, em alguns casos, não são excludentes, e nem haveria razão para ser, se tal restrição exclui a tutela aos menores, presumidamente vulneráveis.

2 Supremo Tribunal Federal. Recurso Extraordinário: 898.060. São Paulo. Rel. Min. Luiz Fux. 21 set. 2016. 
Perquire-se, na senda dos argumentos veiculados, acastelar a multiparentalidade toda vez que esta se apresentar no universo fático, por ser essa a medida que tutela da melhor forma os interesses de todos os envolvidos, além de estar de acordo com os princípios constitucionais.

A um dos pais, não pode ser decretado invisibilidade de sua condição, fechando os olhos para sua situaçáo de posse do estado filho. Isto fere a dignidade da pessoa humana e, quando envolve um menor de idade, o desmanta da proteção integral inerente ao sistema constitucional vigorante (CARDOSO, 2016).

Dispondo desse mesmo entendimento, destaca Maria Berenice Dias (2015 s.p):

Não reconhecer a multiparentalidade é excluir direitos do filho, por não impor os deveres decorrentes do poder familiar a um dos pais. Mas o mais perverso resultado desta omissão é condenar um dos vínculos de filiação à invisibilidade. Não estabelecer deveres e não cobrar o cumprimento de obrigaçôes a quem exerce funções parentais é fomentar a irresponsabilidade.

Comprovada a posse de estado de filho com relação a mais de duas pessoas, todos os pais devem assumir os encargos decorrentes do poder familiar.

A obrigatoriedade em escolher entre duas figuras parentais representaria uma escolha de Sofia às avessas. Inegavelmente, não haveria escolha correta, pois a escolha por si só fere os direitos e garantias fundamentais da pessoa humana.

Nesta seara, dissertando sobre a cumulação de todos os eventos jurídicos na tridimensionalidade humana, Pedro Belmiro Welter elucida (2009, p. 232):

O ser humano é um todo tridimensional e, ao mesmo tempo, uma parte genética, afetiva e ontológica, tendo à sua disposição todos os direitos e desejos desses três mundos, uma vez que a existência é uma formação contínua de eventos, pelo que, nas açôes de investigaçôes de paternidade/maternidade genética e afetiva, devem ser acrescidos todos os direitos daí decorrentes, como alimentos, herança, poder/dever familiar, parentesco, guarda compartilhada, nome, visitas, paternidade/maternidade genética e afetiva e demais direitos existenciais.

Dessa maneira, quando as partes buscarem uma decisão declaratória de multiparentalidade, basta o magistrado averiguar se há pluriparentalidade no caso concreto, ou seja, se há mais de um integrante cumprindo uma mesma função parental. Caso positivo, tal realidade deverá constar nos registros do indivíduo, bem como os efeitos dessa parentalidade deveráo ser gerados normalmente.

Como bem desprende o enunciado 9 do IBDFAM (Instituto Brasileiro de Direito de Família), formulado no IX Congresso Brasileiro de Direito de Família, em Araxá, realizado no ano de 2013 "a multiparentalidade gera efeitos jurídicos" (IBDFAM, 2013 s.p).

Deste modo, ante todo o exposto anteriormente, é cristalino que a família, tal qual os tempos e o curso natural do fluxo vital, sofreu e sofrerá mutaçóes em sua constituição. 
Referidas transformações nada mais são do que reflexos da sociedade da época em análise. No mais, insta pontuar que sendo o direito um espelho da sociedade, cabe a este regular e reconhecer as múltiplas formas de família nas suas mais diversas formas.

Em resumo, a forma como a família é constituída pouco importa ao Estado. $\mathrm{Na}$ verdade, importa mais o fato de que esta seja berço da formação e replicação de valores sociais e constitucionais reconhecidos e garantidos pelo próprio Estado.

\section{Consideraçóes finais}

A origem da família e as características desta no escoar dos anos foram de suma importância para a compreensão da característica da espécie humana de se agrupar, sobretudo tendo em vista a classificação do homem como um ser gregário. Corroborando ao raciocínio anterior, ficou patente a relevância da família como premissa para a formação da sociedade e, por conseguinte, do Direito.

Ademais, percebeu-se que esta está diretamente atrelada a cultura, tornando-se extremamente volúvel aos valores da sociedade, alterando-se conforme a época e o local. De modo que mudam-se os tempos, alteram as sociedades e transformam-se as famílias.

Observou-se que nas primícias do desenvolvimento humano, os filhos eram considerados comuns a todos os integrantes da tribo devido à prática da poligamia e poliandria, comuns na época.

Posteriormente, concluiu-se que a família se atrelou a um caráter machista e religioso. Ainda, em Roma, auferiu um esqueleto estadista. Não obstante, na idade média, em que pese a persistência do machismo, a família perdeu este arcabouço estatal e ganhou função produtiva, vindo esta a desaparecer apenas na idade contemporânea, onde a família deu lugar a um novo ideal familiar face à igualdade de gêneros estabelecida na Constituição Federal de 88 e, infraconstitucionalmente, no Código Civil de 2002.

Denota-se, desse modo, que a família se altera conforme o período histórico, localidade e cultura vivenciada. Ela ignora qualquer ideia pré-estabelecida com o passar dos anos, assim como o ser humano altera seu comportamento com o tempo.

Por via da Constituição de 1988, vários princípios foram inseridos e tamanha foi a relevância destes que a Constituição foi nominada cidadã.

A pesquisa também inferiu que a ideia constitucional de família se apresenta como um conceito implícito, formado com a análise sistemática da Constituição, máxime da carga principiológica ali constante. Desta feita, notou-se que a família constitucional é um modelo aberto com alguns pilares comuns.

Sob esta ótica, a multiparentalidade apresentou-se como uma das consequências possíveis da família reconstituída, sendo ao final advertido que toda vez que aquela se 
apresentar no plano dos fatos, deverá ser judicialmente reconhecida. Tendo em vista o conceito aberto, amplo e inclusivo de família.

\section{Referências}

ARISTÓTELES. Politica. Coleção a obra prima de cada autor. Trad. Politikón, Pedro Constantin Tolens. São Paulo: Martin Claret, 2008.

BRASIL. Supremo Tribunal Federal. Recurso Extraordinário 898.060 São Paulo. Rel. Min. Luiz Fux. 21/09/2016. Disponível em: https:/www.stf.jus.br/arquivo/cms/ noticiaNoticiaStf/anexo/RE898060.pdf

CARDOSO, Graziela Morais. Multiparentalidade Sob A Ótica Da Doutrina Da Proteção Integral. 2016, 61 p. Monografia (Graduação) - Faculdade de Direito. Toledo Prudente Centro Universitário, 2016. Disponível em: http://intertemas.toledoprudente.edu.br/ index.php/Direito/article/view/5297/5042 Acesso em: 08.07.2019

CARNELUTTI, Francesco. Como nasce o Direito. Trad. Ricardo Rodrigues Gama. Campinas: Russell Editores, 2006.

CASSETARI, Christiano. Multiparentalidade e parentalidade socioafetiva. Efeitos jurídicos. 2. ed. São Paulo: Atlas, 2015.

DIAS, Maria Berenice. Manual de Direito das Famílias. São Paulo: Revista dos Tribunais, 2011.

DIAS, Maria Berenice. Três não é Demais! 2015. Disponível em: http://www.ajuris.org. br/2015/02/13/tres-nao-e-demais-por-maria-berenice-dias/ Acesso em 12.06.2019.

ENGELS, Friedrich. A origem da família, da propriedade privada e do Estado. São Paulo: Global Editora, 1986.

FARIAS, Cristiano Chaves de. NETTO, Felipe Braga. ROSENVALD, Nelson. Manual de Direito Civil. Salvador: Editora Juspodivm, 2019.

FERREIRA, Jussara Suzi Assis Borges Nasser. RÖRHMANN, Konstanze. As Famílias Pluriparentais ou Mosaicos. Revista do Direito Privado da UEL - Volume 1 - Número 1 Disponível em: http://www.uel.br/revistas/direitoprivado/artigos/ Fam\%C3\%ADliasPluriparentaisouMosaicosJussaraFerreira.pdf Acesso em 18.06.2019

FILHO, Roberto Lyra. O que é Direito. São Paulo: Brasiliense, 2006.

FONSECA, Lorena; CARRIEN, Alexandre de Pádua. O abandono afetivo deve ser indenizado? Reflexôes jurídicas, psicológicas e sociais. Revista Direito e Justiça: Reflexóes Sociojurídicas, Santo Ângelo, v. 19, n. 35, p.13-40, set./dez. 2019. Disponível em: 
http://srvapp2s.urisan.tche.br/seer/index.php/direito_e_justica/article/view/2700/1892. Acesso em: 07 nov. 2019

GAGLIANO, Pablo Stolze. FILHO, Rodolfo Pamplona. Manual de Direito Civil. São Paulo: Saraiva, 2017.

GESSE, Eduardo. Família Multiparental: reflexos na adoção e na sucessão legítima em linha reta ascendente. Curitiba: Juruá, 2019.

GODOY, Sandro Marcos. A mulher e o Direito do Trabalho: a proteção e a dimensão constitucional do princípio da igualdade. Birigui: Editora Boreal. 2015.

GODOY, Sandro Marcos. Gênese do Direito: as primeiras leis e obrigações. Revista Pensamento Jurídico, São Paulo, Vol. 9, no 1, jan./jun. de 2016, p. 9-26.

GODOY, Sandro Marcos. O Meio Ambiente e a Função Socioambiental da Empresa. Birigui: Editora Boreal. 2017.

INSTITUTO BRASILEIRO DE DIREITO DE FAMÍLIA. Enunciados do IBDFAM. Disponível em: http://www.ibdfam.org.br/conheca-o-ibdfam/enunciados-ibdfam Acesso em 14.04.2019

LÔBO, Paulo Luiz Netto. Direito ao estado de filiação e direito à origem genética: uma distinção necessária. Jus Navigandi, Teresina, ano 9, n. 194, 16 jan. 2004 . Disponível em: http://jus.com.br/revista/texto/4752. Acesso em: 06 nov. 2019.

MORGAN, Lewis Henry Morgan. Ancient Society. Chicago: Sharles H. Kerr \& Company Disponível em: https://archive.org/stream/ ancientsocietyor00morg? ref=ol\#page/n5/mode/2up Acesso em 29.07. 2019.

NOGUEIRA, Jacqueline Filgueiras. A filiação que se constrói. O reconhecimento do afeto como valor jurídico. São Paulo: Memória Jurídica, 2001.

NOVELINO, Marcelo. JÚNIOR, Dirley da Cunha. Constituição Federal para Concursos. Salvador: Editora Juspodivm, 2017.

PACHÁ, Andréa Maciel. A vida não é justa. Rio de Janeiro: HarperCollins Brasil, 2016.

PINTO, Tales dos Santos. Idade moderna. Disponível em: http://www. mundoeducacao.com/historiageral/idade-moderna.htm Acesso em 02.07.2019

PÓVOAS, Mauricio Cavallazzi. Multiparentalidade: a possibilidade de múltipla filiação registral e seus efeitos. Florianópolis: Conceito, 2012.

RAWLS, John. The Law of Peoples. Cambridge: Harvard University Press, 1999.

ROCHA, Marco Túlio de Carvalho. O conceito de família e suas implicaçóes Jurídicas: teoria sociojurídica do direito de família. Rio de Janeiro: Elsevier, 2009. 
SCHWERZ, Vanessa Paula. Multiparentalidade: possibilidade e critérios para o seu reconhecimento. Revista do CEJUR TJSC: Prestação jurisdicional, Florianópolis, v. 1, n. 3, p.192-221, dez. 2015. Disponível em: https://revistadocejur.tjsc.jus.br/cejur/article/ view/98 . Acesso em: 07 nov. 2019.

TEIXEIRA, Ana Carolina Brochado. RODRIGUES, Renata de Lima. $A$

Multiparentalidade como Nova Estrutura de Parentesco na Contemporaneidade. E-Civitas - 2013 - Volume 6 - Número 02 Disponível em: http://revistas.unibh.br/index.php/ dcjpg/article/view/1179 Acesso em 20.06.2019

VILLELA, João Baptista. Desbiologização da Paternidade. Revista da Faculdade de Direito de Minas Gerais. N. 21, 1979, p. 400-418. Disponível em: http://www.direito. ufmg.br/revista/index.php/revista/article/view/1156/1089 Acesso em 14.06.2019.

WELTER, Pedro Belmiro. Teoria Tridimensional do Direito de Família. Porto Alegre: Livraria do Advogado, 2015. 